\title{
Pain Assessment in Emergency Department of Teaching Hospital in Lalitpur
}

\section{Srijana Gauchan}

Lecturer, Department of General Practice and Emergency Medicine, Patan Academy of Health Sciences, Lalitpur, Nepal

\section{Correspondence:}

Contact: srijanagauchan@gmail.com,9841530290

\section{ABSTRACT}

Introduction: Proper pain assessment is directly related to proper pain management. The American pain society (APS) in 1996 instituted "the pain as the 5th vital sign", in an effort to reduce the burden of underassessment and inadequate pain management. The objective of this study is to find out the practice of pain assessment and to make improvements.

Methods: This was an observational study of pain assessment by the medical officer in the emergency department (ED).Convenience sampling was done at three different shifts in ED. All the data of pain assessment was taken and tabulated and analyzed to know the practice of pain assessment. Standard as set at $80 \%$. In the first stage data collection was done for one month as per convenience. Following the observed finding, in the second stage intervention was done. After this in the third stage re-data collection was done to see the improvement.

Results: A total of 503 patients were enrolled in this study. Out of this $53 \%(n=265)$ were in the first stage and $47 \%(n=238)$ in the third stage of the study. In the first stage of the study, there was $7 \%$ $(\mathrm{n}=19)$ documentation of numerical rating scale (NRS) and PQRST (P-precipitating and palliating factor, Q-quality of pain, R-radiation, S-site of pain, T-timing of pain) was not documented. After the intervention in third stage documentation of NRS was done in $70 \%(n=167)$ and documentation of PQRST was variable.

Conclusions: The study revealed that the existing practice of pain assessment in the emergency department is poor but after the intervention, there was a remarkable improvement in the pain assessment.

Keywords: Pain, Fifth Vital Sign, Numerical Rating Scale (NRS), Pain Assessment

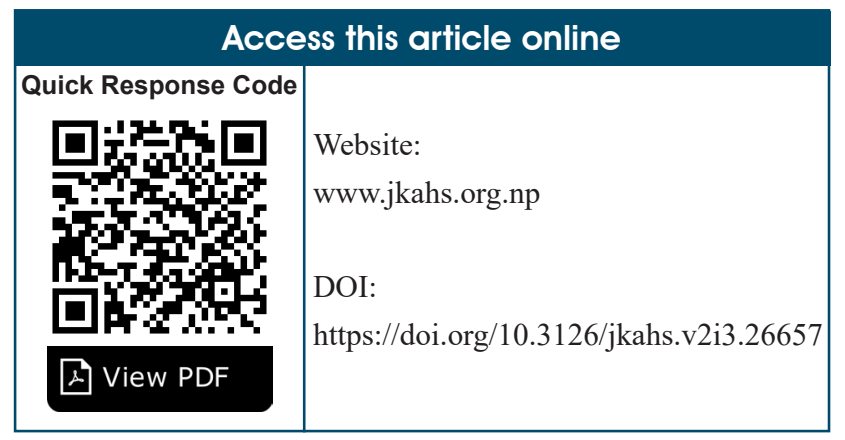

\section{Article Info.}

\section{How to cite this article?}

Gauchan S. Pain Assessment in Emergency Department of Teaching Hospital in Lalitpur. Journal of Karnali Academy of Health Sciences. 2019;2(3): 209-213.

Received: 14 Oct., Accepted: 22 Nov., Published: 11 Dec. 2019

Conflict of Interest: None, Source of Support: None 


\section{INTRODUCTION}

Pain management is a critical component of palliative care but inadequately treated pain remains a global public health problem. ${ }^{1,2}$ Underassessment of pain has been found to be a significant cause of inadequate pain management. ${ }^{3}$ The phrase "pain as the fifth vital sign" was initially promoted by the American Pain Society to elevate awareness of pain treatment among healthcare professionals and to make pain visiable. ${ }^{4}$ They state that pain should be assessed in all patients because effective pain control relies on recognition of pain by regular assessment and appropriate treatment. ${ }^{5}$ The formal assessment of pain is therefore important to initiate and evaluate the effectiveness of pain treatment. ${ }^{6}$ Since pain is subjective, self-report is considered the Gold Standard and most accurate measure of pain. ${ }^{7}$ The assessment subjectivity is reduced by using assessment tool. ${ }^{8}$ The method also aids in the selection of appropriate pain medication and evaluating the response to treatment.7Hence documenting pain is very essential. So, this study is designed to find out the existing practice of documenting pain and an intervention to improve the practice.

\section{MATERIALS AND METHODS}

This was an observational study of the assessment and documentation of pain by the medical officer in emergency department (ED). Convenience sampling was done at three different shift in ED. All the data of pain assessment was taken and tabulated and analysed. This study was conducted at Patan Academy of Health Sciences (PAHS), emergency department from 15th October, 2018 to 14th March, 2019. The Numerical rating scale (NRS) tool was taken because the ED case sheet already had NRS printed for assessment of severity of pain. NRS is valid for use in the assessment of acute, cancer or chronic non-malignant pain and in varied clinical settings. ${ }^{5}$ For general purposes it has good sensitivity and generates data that can be statistically analysed for audit purposes. ${ }^{9}$ Regarding pain history, PQRST (P-precipitating and palliating factor, Q-quality of pain, R-radiation, S-site of pain, T-timing) of pain was used. This method of assessing pain is a valuable tool to accurately describe, assess and document pain. ${ }^{7}$ All case presenting to emergency with the complaint of pain was included in the study and patient of paediatric age group and those who have altered level of consciousness were excluded from the study. Since this was a duration based study, sample size was not calculated however convenience sampling was taken from all three shifts ( 8 am to 1 $\mathrm{pm}, 1 \mathrm{pm}$ to $8 \mathrm{pm}$ and $8 \mathrm{pm}$ to $8 \mathrm{am})$. Standard was set arbitrarily at $80 \%$ based on the consensus of the audit team, considering that pain should be assessed in all patients. So, $80 \%$ of sample should have pain assessment documented.

\section{PQRST assessment}

- Precipitating and relieving factors

- What makes the pain worse? What makes the pain better?

- Quality

- How would you describe the pain? What does it feel like?

- Radiation

- Is the pain in one place or does it move around your body?

- Site and $\mathbf{S}_{\text {everity }}$

- Where is your pain? On a scale of $0-10$, how bad is your pain?

- Timing and $\mathbf{T}_{\text {reatment history }}$

- When did pain start? How often do you get it?

- What are the patterns of the pain? Is it constant, or does it come and go?

- Are you or have you been on treatment for the pain? Does it help?

The study was divided into three stages (figure 3). In first stage data collection was done for one month as per convenience by the investigator. The data collection was done by collecting all the case sheet with the pain as chief complaint, who were already been evaluated by duty doctor who were blinded in the first stage of study and the status of pain documentation was noted. Data was tabulated and analyzed to know the existing practice of pain documentation. The observed finding was compared against standard.

Following this, in the second stage intervention was planned. All the medical officers working in ED, total 35 medical officers were oriented using NRS and PQRST tools. It was done by PowerPoint presentation and bedside teaching once a week for one month at ED classroom. The main objective of the intervention was to highlight importance of pain assessment and 
use of pain assessment tool. Personal and group communication through mobile application was done to emphasize the importance of documenting pain. Pain assessment tools (NRS and PQRST) were attached with the case sheet. This was done over the period of one month. After this in third stage re-data collection was done for one month to see the impact of intervention. And the observed finding in re data collection was again compared against standard. Data analysis was done using EXCEL software.

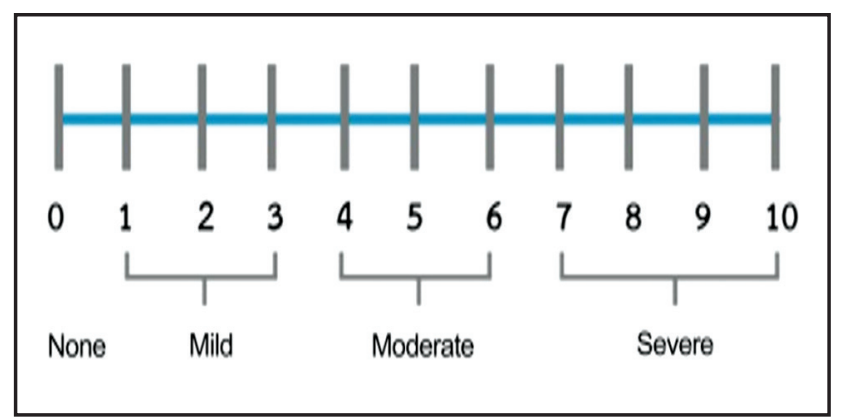

Figure 1: Numerical Rating Scale (NRS)

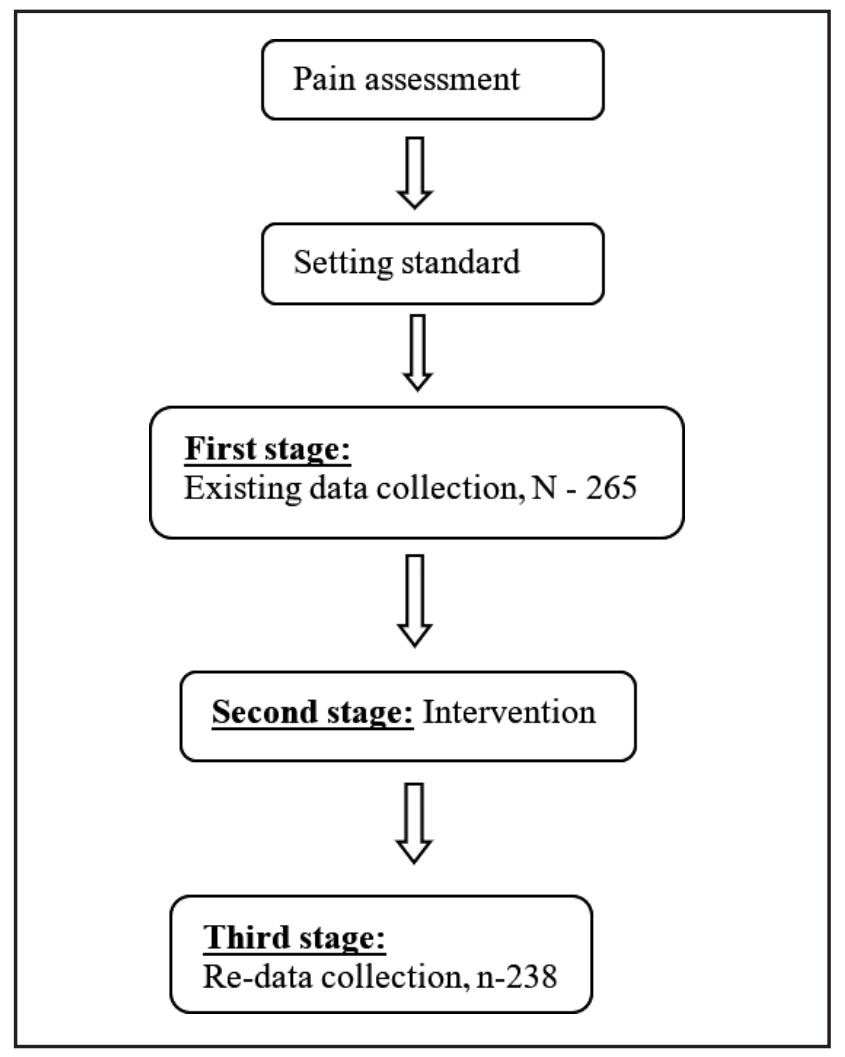

Figure 2: PQRST Assessment

\section{RESULTS}

A total of 503 patients were enrolled in this study. Out of this $53 \%(n=265)$ were in first stage and $47 \%(n=238)$ were in third stage of the study. There was equal distribution of sample between male and female in both the stage, there were $43 \%$ male and $54 \%$ female in the first stage and in third stage $41 \%$ male and $59 \%$ female(table 1).According to age distribution maximum were between 15-35 years in both the stage (table 2). In first stage of the study there was $7 \%(n=19)$ documentation of NRS and PQRST was not used. After intervention in third stage documentation of NRS was assessed in 70\% $(n=167)$ and documentation of PQRST were variable: P-47\% $(n=112), Q-60 \% \quad(n=142), R-59 \% \quad(n=140), S-95 \%$ $(\mathrm{n}=225)$ and T-94\% $(\mathrm{n}=223)$.

The bar diagram (figure 4) shows the comparison of first stage and third stage data against standard where NRS was used in only 7\% of the cases for pain assessment while PQRST was not documented at all in the first stage while in the third stage there was remarkable change in the documentation of pain assessment, NRS was documented in $70 \%$ of the cases and PQRST was also documented for which the data were variable. Table 3 also enlist the data of first stage and third stage along with the standard.

\section{Table 1: Sex Distribution}

\begin{tabular}{lcc}
\hline \multicolumn{1}{c}{ Sex } & First stage $\%$ & Second stage $\%$ \\
\hline Male & 43 & 41 \\
Female & 57 & 59 \\
\hline
\end{tabular}

Table 2: Age Distribution

\begin{tabular}{ccc}
\hline Age in year & First stage \% & Second stage \% \\
\hline $15-35$ & 48 & 54 \\
$36-55$ & 23 & 28 \\
$>55$ & 29 & 18
\end{tabular}




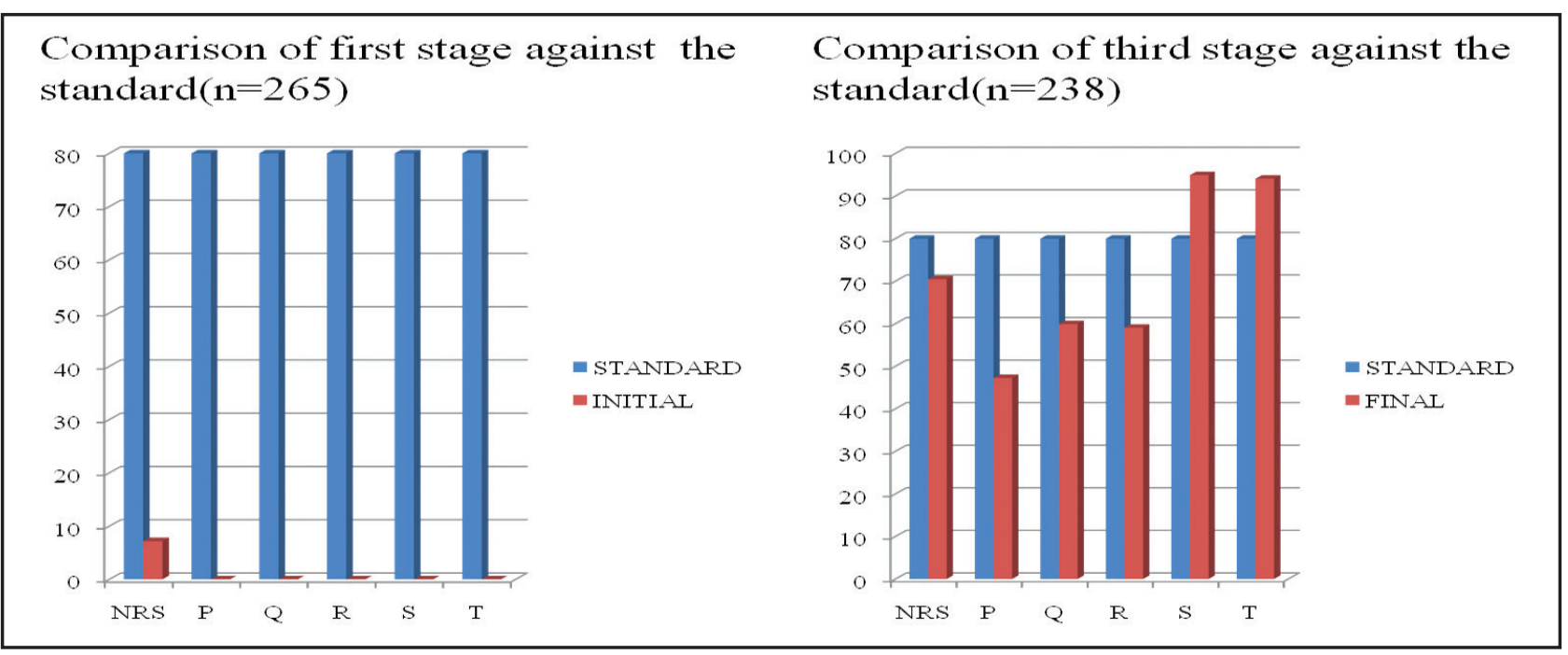

Figure 4: Comparison of findings of first and the third stage of the study against the standard

Table 3: Comparison of NRS/PQRST in the first and third stage against the standard

\begin{tabular}{cccc}
\hline & Standard \% & First stage \% & $\begin{array}{c}\text { Third } \\
\text { stage\% }\end{array}$ \\
\hline NRS & 80 & 7.16 & 70.46 \\
P & 80 & 0 & 47.25 \\
Q & 80 & 0 & 59.91 \\
R & 80 & 0 & 59.07 \\
S & 80 & 0 & 94.93 \\
T & 80 & 0 & 94.09 \\
\hline
\end{tabular}

\section{DISCUSSION}

In first stage of this study revealed patients did not receive optimal pain assessment in ED, only $7 \%$ of the patients were assessed for the severity of pain. Although the tool was present in the patient's record sheet but it was underutilized. This is similar to another study where hospitals have guidelines for pain assessment but they struggle with low compliance with pain documentation, only $49.2 \%$ of the patients were assessed. ${ }^{10}$ This might be due to lack of Knowledge and understanding of pain assessment.

A systematic review of interventions to improve pain management reported that almost half of the interventions incorporated pain scoring either as a stand-alone intervention or as part of a multifaceted intervention. The review demonstrated that, although increasing visibility and access to pain scoring tools improved documentation of pain, there was inconsistent evidence of a corresponding improvement inpatient access to analgesia. ${ }^{11}$

Many studies have shown that PQRST method of assessing pain is a valuable tool to accurately describe, assess and document a patient's pain. ${ }^{7}$ The method also aids in the selection of appropriate pain medication and evaluating the response to treatment. ${ }^{7}$ Where as in my initial audit the tool was not used.

So, due to this, the intervention planned was in the form of orientation. The objective of the intervention was to create awareness and improve knowledge amongst doctors. After the intervention, final study did show improvement compared to the initial one. So, this states that intervention in a form of orientation can make a big difference. Doctors might have ignored pain assessment due to lack of knowledge or understanding pain empathically. Dr James Campbell, president of American pain society in 1996 said "if pain were assessed with the same zeal as other vital signs are, it would have a much better chance of being treated properly."4 Many studies have shown that assumption about patient's pain intensity are inaccurate in many settings and documentation of pain assessment has improved pain management. ${ }^{12,13}$ Introducing pain as fifth vital sign along with other vital signs is a method to improve pain management thus asking for pain scores is important step towards excellent management. ${ }^{14}$ Therefore it is necessary 
to understand, assess and document pain. Regular auditing is one of the important tool that can make difference. $^{15}$

Turnover of the medical officers in the ED and incomplete documentation of pain in the case sheet were my limitations. Design of the study could have been better if I had collected data of the outcome after the assessment which could have had more impact on the study.

\section{CONCLUSIONS}

Existing practice of pain assessment in the emergency department is poor . There was remarkable improvement in the pain assessment after the intervention. Thus the use of standard tools improve pain assessment and helps to make pain visible, which might reflect on the quality of life of patient as well.

\section{Acknowledgement}

To all the staff and patients of department of GP/ED, Patan academy of health science

\section{REFERENCES}

1. Tiruvudana M, Saraswathidevi P. Management of pain. In: Methews L, editor. Textbook for certificate course in essentials of palliative course. Calicut:IndianAssociation of Palliative Care; 2018. p. 59-90.

2. Cleary JF, Maurer MA. Pain \&policy studies group. Two decades of working to address regulatory barriers to improve opioid availability and accessibility around the world. Journal of Pain and Symptom Management. 2018;55(2S):121-34.

3. National Pharmaceutical Council, Berry PH, Chapman CR, Covington EC, Dahl JL, Katz JA, Miaskowski C, McLean MJ, editors. Pain: current understanding of assessment, management and treatments. Washington, DC: National Pharmaceutical Council and Joint Commission of Healthcare Organisations; 2001.

4. Veterans Health Administration. Pain as the 5th vital sign toolkit. Rev. Ed. Washington DC: Veterans Health Administration; 2000.
5. Macintyre PE, Scott DA, Schug SA, Visser EJ, Walker SM, editors. Acute pain management: scientific evidence. 3rd ed. Melbourne: Australian and New Zealand College of Anaesthetists and Faculty of Pain Medicine; 2010.

6. Bird J. Assessing pain in older people. Nurs Stand. 2005;19(19):45-52.

7. Crozerkeystone.org, PQRST Pain assessment method [internet]. Springfield, PA: CrozerKeystone Health System [cited 2019 July30]. Available from:https://www.crozerkeystone. org/nurses/pqrst/

8. Schofield P, Dunham M. Pain assessment: how far have we come in listening to our patients? Prof Nurse.2003; 18(5):276-9.

9. Williamson A, Hoggart B. Pain: a review of three commonly used pain rating scales. J ClinNurs.2005;14(7):798-804.

10. Sampson FC, Goodacre SW, O'Cathain A. Interventions to improve the management of pain in emergency departments: systematic review and narrative synthesis. Emerg Med J. 2014;31:e9-18.

11. Dale J, Bjørnsen LP. Assessment of pain in a Norwegian Emergency Department. Scand J Trauma ResuscEmerg Med. 2015;23:86. doi:10.1186/s13049-015-0166-3

12. Voight L, Paice JA. Standardized Pain Flowsheet: Impact on Patient Reported Experiences after Cardiovascular Surgery. Am J Crit Care. 1995;4:308- 313.

13. Guru V, Dubinsky I. The Patient versus Caregiver Perception of Acute Pain in the Emergency department. J Emerg Med. 2000;18:7-12

14. Baharuddin KA, Mohamad N, Rahman NH, Ahmad R, Him NA. Assessing patient pain scores in the emergency department. Malays JMed Sci. 2010;17(1):17-22.

15. Limb C, Fowler A, Gundogan B, Koshy K, Agha R. How to conduct a clinical audit and quality improvement project. Int $\mathrm{J}$ SurgOncol. 2017;2(6):e24. doi:10.1097/ IJ9.0000000000000024 